\title{
ENHANCING POST DISASTER RECOVERY BY OPTIMAL INFRASTRUCTURE CAPACITY BUILDING
}

\author{
Abhijeet Deshmukh ${ }^{1}$, Makarand Hastak ${ }^{2}$ \\ ${ }^{1}$ PhD Candidate, Hampton Hall of Civil Engineering, Purdue University, USA. E-Mail: deshmukh@purdue.edu \\ ${ }^{2}$ Head and Professor of Construction Engineering and Management, Professor of Civil Engineering, Purdue University, USA, \\ E-Mail: hastak@purdue.edu
}

\begin{abstract}
When the services of infrastructure systems necessary for the operation of other infrastructure are compromised due disaster impacts, the recovery is hampered. For example, the delivery of basic aid and relief in Haiti and Philippines was hampered as vital infrastructure such as transportation network, communications, electricity, water supply and sanitation failed to provide required services. Additionally, a gap is created between the demands arising in post disaster recovery and the services available. As a result, the response and recovery activities are not able to meet the community demands that delay the overall recovery. Strategic capacity building of infrastructure is needed that will allow decision makers to fill the gap created in a timely manner. This research will enable the decision makers to take into account the availability of auxiliary capacities that will be able to complement the reduced services of supporting infrastructure. This paper presents an optimization model to assure the delivery of desired services in post disaster recovery through optimal infrastructure capacity building. The model uses genetic algorithm for optimal capacity selection. It has a single objective function that minimizes cost of using capacities to meet the demand on a daily basis.
\end{abstract}

Keywords: resilience, capacity building, infrastructure serviceability, hospitals, water supply

$* * *$

\section{INTRODUCTION}

The impact of natural disasters in a region is further escalated by lack of capacities such as reduced infrastructure serviceability and inadequate vital resources required for recovery. Often, existing capacities are unable to support post disaster recovery in different phases, i.e., emergency, short term recovery or restoration and long term recovery. For example, the response and recovery in Philippines were impacted by limited services offered by damaged infrastructure such as transportation, communication, power, water and governing agencies (Lum and Rhoda 2014). This became one of the fundamental challenges associated with infrastructure that were fundamental for the operations of other infrastructure and recovery activities. The lack of support from the infrastructure created physical and logistic challenges due to which the worst stricken areas were not able to receive relief supplies within desired time.

Hurricane Yolanda caused major disruption to infrastructure services such as food, water, telecommunications, and electricity. The National Grid Corporation of the Philippines (NGPC) estimated that approximately 2,000 major distribution and transmission facilities were damaged (AbiSamra et al. 2014). Lack of electricity not only impacted the services of health infrastructure but also increased the risks in maintaining cold chains and storing vaccines (Chiu 2013). Additionally, lack of leadership in governing agencies impacted the coordination between actors involved in recovery and response resulting in delayed recovery (Lum and Rhoda 2014). As a result, the severity of impact increased and delayed the overall recovery.
There is a need to i) identify the gap created between community demand and available infrastructure services, ii) find alternatives, i.e., auxiliary capacities for filling the gap and iii) optimally select the alternatives for infrastructure capacity building. This paper presents a transformative research approach that will help the decision makers for optimal infrastructure capacity building. The optimization model is a part of a larger research work focused on the development of decision support system (DSS) (Deshmukh and Hastak 2014). Decision makers will be able to develop effective response and recovery strategies at various levels, i.e., local, state and national for meeting community demands in desired time. This research adopts the definition of resilience proposed by the UNISDR (2011). Resilience is the ability of a system, community or society exposed to hazards to resist, absorb, accommodate to and recover from the effects of a hazard in a timely and efficient manner, including through the preservation and restoration of its essential basic structures and functions.

\section{PRIOR RESEARCH WORK}

Recovery is a complex process consisting of loosely based set of activities that enables the community to return to a pre disaster level by restoring or even improving the community attributes such as health, livelihoods, security (Garnett and Moore 2010). It is a holistic approach where different actors play simultaneously in stabilizing the disaster impact within a community. It involves an effective decision making process that allows the community to return to either pre 
disaster or better levels within desired time. Recovery is supported by factors such as availability of resources and funds, available infrastructure capacities, effective leadership, and planning and implementation of response and recovery strategies. Additionally, improving the resilience of critical lifelines such as water and power and critical facilities and functions such as emergency response management is critical for overall community resilience. Infrastructure plays an important role in the disaster recovery as it provides vital services to the community, serving as "the backbone" of any community (Bruneau et al. 2003; Vugrin et al. 2010). The lifeline services help the community to restore its social functions such as health services, education, livelihood and economic functions such as business, production, manufacturing, etc. (Rose and Liao 2005; Bruneau et al. 2003; Oh et al. 2012).

Disrupted infrastructure services are unable to support recovery and impact the regions both socially and economically. (Chang et al. 2002; Blake et al. 2011; Chiu 2013; Zhang et al. 2013). Lack of infrastructure services during post disaster recovery increases the risk of failure of critical recovery and sustaining activities such as health, housing education, restoration, logistics and debris removal (Comfort et al. 2011;Blake et al. 2011). Comfort et al. (2011) examined the challenge faced by the Haitian government during the recovery process due to unavailability of lifeline infrastructure such as transportation networks, communication, electrical, water, waste and other facilities. According to Miles and Chang (2006), infrastructure performance over time could be used to assess community recovery. Similarly, Chang and Shinozuka (2004) have proposed that a broader understanding is required for improving resilience which should not be limited to minimizing monetary losses. Additionally, there is a need to focus on delivery of infrastructure service that would help the decision makers to address post disaster demands, quality of service and managing flow of service. While there are significant research results available in developing loss models for post disaster recovery, measuring recovery with progression of time has largely been neglected (Miles and Chang 2006).

\section{INFRASTRUCTURE SUPPORT}

TO

\section{COMMUNITY RECOVERY}

Infrastructure play an important role in not only sustaining the communities during normal situation but also support the community recovery after a disaster. In this research, infrastructure is classified into six different types, i.e., civil infrastructure that includes utility systems, transportation systems, etc., civic infrastructure such as hospitals, emergency centers, etc., social infrastructure such as religious centers, homes, and businesses, environmental infrastructure such as watershed, financial infrastructure such as savings, community funds, and educational infrastructure that provide education on capacity development programs, education regarding disaster preparedness and disaster management (Table 1).

Table 1 Six infrastructure supporting community/infrastructure recovery

\begin{tabular}{|c|c|c|c|c|c|}
\hline Civil & Civic & Social & Environmental & Financial & Education \\
\hline $\begin{array}{c}\text { Utility } \\
\text { Systems }\end{array}$ & $\begin{array}{c}\text { Emergency } \\
\text { Centers }\end{array}$ & Homes & Landscape & $\begin{array}{c}\text { Disaster } \\
\text { Funds }\end{array}$ & Training \\
\hline $\begin{array}{c}\text { Water, Gas, } \\
\text { Electricity }\end{array}$ & Hospitals & $\begin{array}{c}\text { Religious } \\
\text { Centers }\end{array}$ & Wastelands & Insurance & Programs \\
\hline $\begin{array}{c}\text { Transportatio } \\
\text { n Systems }\end{array}$ & Police, etc. & $\begin{array}{c}\text { Community } \\
\text { Centers }\end{array}$ & & Donors & $\begin{array}{c}\text { Feedback } \\
\text { Mechanism }\end{array}$ \\
\hline $\begin{array}{c}\text { Roads, } \\
\text { Bridges, etc. }\end{array}$ & $\begin{array}{c}\text { Governance, } \\
\text { etc. }\end{array}$ & NGOs & & & \\
\hline
\end{tabular}

Capacity is defined as the combination of all the strengths, attributes and resources available within a community, society or organization that can be used to achieve agreed goals. Each infrastructure has a zone of influence (ZOI) based on the interrelationships among infrastructure and the community (Oh et al. 2012). The intersection between ZOI illustrates the interrelationship between infrastructure. These infrastructure support the sustaining and recovery activities of a community or an industry. When these are not adequately supported by infrastructure and the resources, a gap is created between the community demands and the services available from infrastructure. Therefore, it takes longer for adequately meeting the community needs that escalates the impacts on the community.

\section{RESEARCH FRAMEWORK AND OBJECTIVES}

The general objective of this paper is to help decision makers develop strategies by addressing the provision of auxiliary capacities in the event of supporting infrastructure failure during post disaster events. The specific objective of this paper is to present an optimization model for selecting capacities that will help decision makers for meeting the daily requirements of the community under give conditions. The explanation of the optimization model is provided using 
a hypothetical situation for water demand of the hospital where in auxiliary capacities are optimally built to complement reduced civil infrastructure system services. This approach allows the hospital to adequately meet its daily water needs in absence of required services from city water supply network. The following section describes the hypothetical situation.

\section{DESCRIPTION \\ OF \\ OPTIMAL \\ INFRASTRUCTURE CAPACITY BUILDING THROUGH A HYPOTHETICAL SITUATION}

The optimization model is explained using the relationship between city water supply network and a hospital. In this case, Hospital A is a large hospital with a 700 bed facility. The hospital uses water in running the HVAC, boilers, cooling towers, sterilization procedures, kitchen, laundry, cleaning, irrigation of lawns, and domestic purposes (EIA 2012). The average consumption of water for large hospitals is 139,124 gallons per day of water (based on EIA 2012). Many hospitals have developed emergency planning guide for the event of failure of lifeline services. However, the daily potable water needs of the hospital are beyond the stockpiling capacity for such emergencies (Welter et al. 2013). The hospitals should seek different approaches for satisfying the daily demand.

\begin{tabular}{|l|l|l|}
\hline \multicolumn{2}{|l|}{\begin{tabular}{l} 
Legend \\
\hline WTP
\end{tabular}} & $\begin{array}{l}\text { Water Treatment Plant } \\
\text { Power Grid providing } \\
\text { electricity to the } \\
\text { community }\end{array}$ \\
\cline { 2 - 3 } & $\begin{array}{l}\text { Power } \\
\text { Netribution } \\
\text { distribution }\end{array}$ \\
\hline Waste Management & $\begin{array}{l}\text { Connectivity to the } \\
\text { community }\end{array}$ \\
\hline
\end{tabular}

Figure 1 Infrastructure supporting hospital

The daily water needs of the hospital are adequately met by the city supply network during normal conditions. Consider a hospital network located in an urban city in the United States. Under normal conditions, civil infrastructure systems such as power, gas, water supply, waste water management, and transportation support the hospital in providing medical services (Figure 1). Suppose, a severe earthquake occurs close to the city region and impacts the communities, industries and infrastructure. The hospital network might be able to withstand the earthquake and would be able to function at pre disaster level only if the supporting infrastructure can provide the necessary service. However, the supporting civil infrastructure systems might not be able to provide the required services due to their post disaster condition.

Welter et al. (2013) have highlighted the importance of cross sector planning for water supply to hospitals during emergency events. Failure of city water supply to hospitals could lead to cascading failure of critical components in hospitals such as cooling systems resulting in complete cessation. Welter et al. (2013) conducted a water audit on a large hospital in United States that revealed that the hospital was able to curtail its daily normal water demand by approximately $50 \%$ without compromising the essential services to the community (Welter et al. 2013). It is assumed that Hospital A is able to curtail its daily water demand by approximately $50 \%$ during emergency situation. As shown in Table 2, there are three water demand levels of the hospital, i.e., critical demand, essential demand, and normal demand. Critical water demand allows the hospital to functionally operate as a system in both pre and post disaster situation. If the critical demand is not met, the hospital will cease to operate. The essential demand is the minimum water required to provide basic medical services. And normal demand is the pre disaster water requirement. The scope of this paper focuses on optimal selection of auxiliary capacities to meet the daily normal demand of hospital under the absence of desired water supply services. 
Table 2 Daily water demand of hospital

\begin{tabular}{|l|l|l|}
\hline Sr. No. & Type of Demand & Quantity (GPD) \\
\hline 1 & Critical Demand & 150,000 \\
\hline 2 & Essential Demand & 180,000 \\
\hline 3 & Normal Demand & 300,000 \\
\hline
\end{tabular}

\section{WATER SUPPLY NETWORK}

Water from the treatment plant is conveyed through the city's water distribution network. The damage to the water treatment plant and the distribution network damaged due to the earthquake compromises the city water supply services. In this situation, city water supply is unable to meet the daily demands of Hospital A and produces a cascading failure. As a result, the hospital ceases to function. Soon after the disaster, public utilities assess the damage on infrastructure to include losses, physical damage to infrastructure assets, and service losses. This assessment complements the recovery and restoration of the infrastructure and based on the available capacities such as manpower, equipment, funds available, etc., the utility service providers are able to i) prioritize restoration, and ii) estimate the restoration of services of infrastructure over time. The scope of this paper excludes the design and formulation of serviceability curves of the infrastructure systems. The serviceability curve of the water supply network is represented by a progressive S-curve. Additionally, the serviceability curve provides information regarding the amount of water (in gallons per day) which is available at the hospital. It is assumed that the equation incorporates the system and conveyance water losses and provides the net water available at the hospital.

According to the water utility, the city water supply is able to meet the daily normal demand by the $60^{\text {th }}$ day. As mentioned earlier, the scope of this paper focuses on the optimal selection of capacities for Hospital A when the city water supply network is not able to meet the daily normal water demand. Thus, it can be understood that till the $60^{\text {th }}$ day, a gap is created between the daily normal water demand and city water supply service. If Hospital A is unable to function, then unavailability of medical services could likely increase the risk of i) malnutrition, ii) diseases with respect to natural hazards, and iii) deaths.

\section{SUPPORT FROM OTHER INFRASTRUCTURE}

During response and recovery phase of disaster, several infrastructure come in to support the hospital. For example, civic infrastructure such as the government may send a group of medical professionals to the disaster prone areas, the local governing agencies may set up capacities such as surface water pumps, and mobile tankers to meet the potable water need of the hospital. During the flooding of Red River in 1997, the water treatment plant at Grand Forks, North Dakota failed that resulted in the failure of the health care facilities. Nearly 1000 patients and senior residents were evacuated and the city was without any health services for a period of 18 days. Civic infrastructure, i.e., National Guards provided temporary services by setting up reverse osmosis treatment system till the city water supply services were restored (Reed 1998; Siders and Jacobson 1998). In this hypothetical situation, social infrastructure such as not for profit organizations and religious institutions, civic infrastructure such local municipal corporations, or private parties and other entities step in to provide auxiliary services to the Hospital (Figure 2). The capacities available from "non" civil infrastructure collectively will be able to meet the water demand of the hospital.

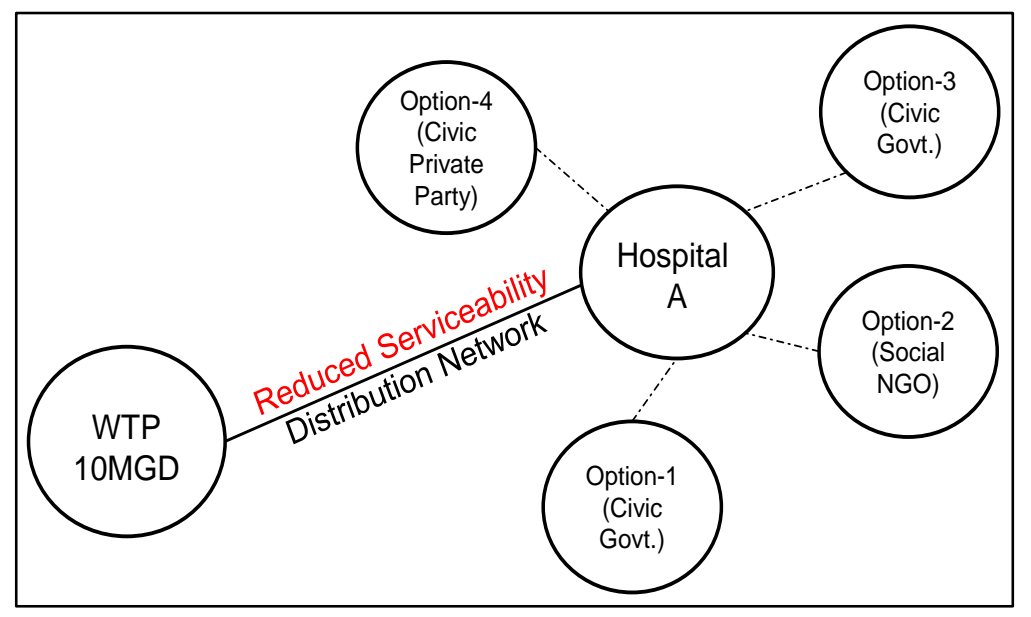

Figure 2 Support from other infrastructure during post disaster recovery (Water from city water supply is not able to meet the daily demand of the hospital)

\section{OPTIONS AVAILABLE}

As mentioned earlier, during post disaster recovery, the capacities available from sources like government, donor organizations and other agencies might be able to collectively meet the water demand. However, these options might have certain limitations, restrictions that may affect meeting daily water demand. The options available for meeting the daily water demand have the following characteristics: - 
i) Number of options available. For example, auxiliary capacities may include water tankers, water pumps, emergency water purification system (EWPS), bottled waters for specific operations, etc.

ii) Number of units available within each option

iii) Volume of unit

iv) Day from when option is available

v) Duration of availability, and

vi) Cost associated per unit.

This information will be helpful in mathematical design of the model. The options could be selected such that the daily selected capacities have a minimum cost. Finding set of alternatives that are optimal (in this case, minimal cost) could be achieved using optimization algorithm. The problem defined in this paper could be solved either using linear programming or genetic algorithm. Genetic algorithm is selected in order to handle discrete data. Prior research work on genetic algorithm and its usage in disaster relief and disaster management field is excluded from this paper due to word limitations.

\section{MATHEMATICAL FORMULATION}

In this section, the information provided in the hypothetical situation is used to design the optimization problem. This section firstly, consists of the parameters, decision variables and objective functions. Following that, the objective function is developed and lastly, the constraints of the problem are explained. The explanation of the mathematical model in this paper is excluded.

\section{PARAMETERS}

Options $_{\mathrm{i}}=$ number of options available for meeting the hospital demand

N_options $\mathrm{s}_{\mathrm{i}}=$ number of units available with each option $\operatorname{cost}_{i}=$ cost of using one single unit of option ${ }_{i}$ opt_cap i $_{i}$ capacity of each unit of option opt_start ${ }_{i}=$ day when the option ${ }_{i}$ is available opt_dur ${ }_{\mathrm{i}}=$ number of days for which option $_{\mathrm{i}}$ is available where, $\mathrm{i} \in \mathrm{I}, \mathrm{I}=1,2,3,4, \ldots \ldots . \mathrm{n}$

Table 3 Parameters of options (Abundant resources available)

\begin{tabular}{|c|c|c|c|c|c|c|}
\hline Sr. No. & Option & $\begin{array}{c}\text { Option capacity } \\
\text { (Gallons) }\end{array}$ & $\begin{array}{c}\text { Number of } \\
\text { units (\#) }\end{array}$ & $\begin{array}{c}\text { Cost of using each } \\
\text { unit (in dollars) }\end{array}$ & $\begin{array}{c}\text { When available } \\
\text { (day) }\end{array}$ & $\begin{array}{c}\text { Duration of } \\
\text { availability (day) }\end{array}$ \\
\hline 1 & Option-1 & 2300 & 50 & 2290 & 1 & 77 \\
\hline 2 & Option-2 & 1500 & 50 & 1500 & 1 & 77 \\
\hline 3 & Option-3 & 1260 & 55 & 1280 & 1 & 77 \\
\hline 4 & Option-4 & 1200 & 55 & 1250 & 1 & 77 \\
\hline
\end{tabular}

Note: Table 3 shows the parameter values under the abundant resources scenario. In this case, each option is available from the $1^{\text {st }}$ day till the $77^{\text {th }}$ day (which exceeds the $60^{\text {th }}$ day, i.e., water supply network is able to meet the normal daily demand). Additionally, each option has 50 units which reflect that abundant resources are available.

\section{DECISION VARIABLE}

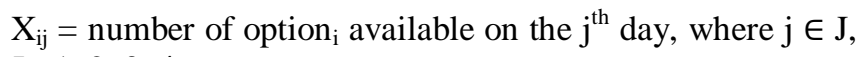
$\mathrm{J}=1,2,3,4, \ldots \ldots \ldots . \mathrm{m}$

Objective function

Minimize cost, where

cost $=\mathrm{X}_{\mathrm{ij}}$ *opt_cap $_{\mathrm{i}}$

(1)

\section{Constraints}

The objective function is subjected to two constraints in this optimization model: -

i) Limited resources available,

ii) Limited budget available to invest in optimal selection.

\section{RESULTS}

Genetic algorithm is a problem solving method to find approximate solutions to optimization and search problem. GA is uses the concept of natural selection based on genetics in problem solving (Sumathi and Paneerselvam 2010). GA starts with a randomly generated population that represents possible solutions to the problem. Parents are selected from one population to form new solutions based on their fitness measure. The next generation population is expected to provide better results than the older generation. The process is repeated several times that drives the result towards global optimal solution (Sumathi and Paneerselvam 2010). It is an evolutionary algorithm that will identify set of auxiliary capacities, i.e., number of units selected under each option for filling the gap created each day. The capacities selected will have their cost minimal. For example, there might be set 1 and set 2 that are able to fill the gap on the $\mathrm{j}^{\text {th }}$ day. However, the collective cost of set 1 being less than set 2 will be selected. The optimization model continues to identify daily optimal capacities with minimal cost till the city water supply is able to meet the daily normal water demand. Table 4 shows the optimization results under various conditions. 
Table 4 Results of Simulations

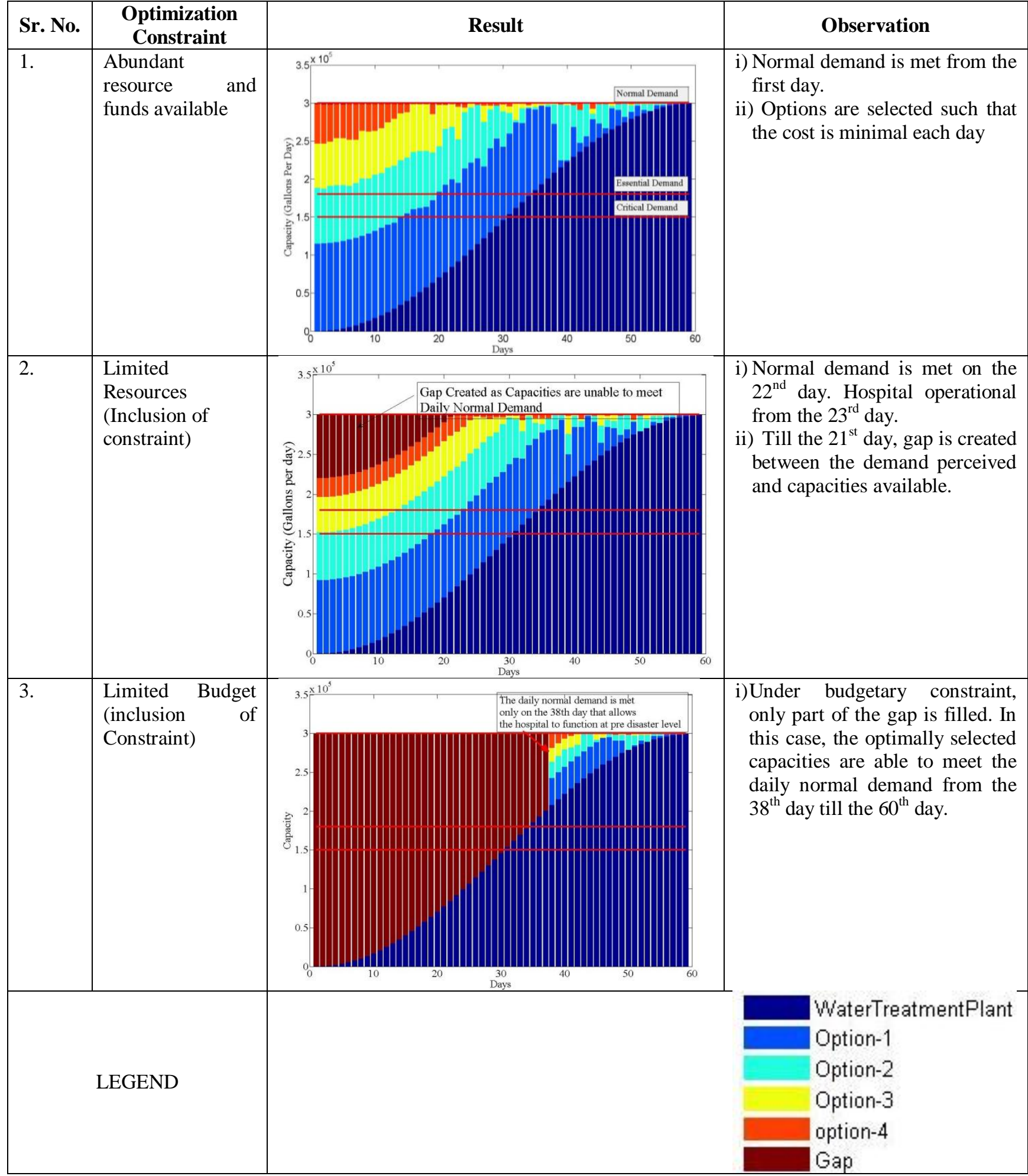

\section{DEVELOPMENT OF STRATEGIES}

This research will help the decision makers to prepare effective response and recovery strategies during response and recovery phases. Additionally, this research will allow the integration of decisions taken during emergency and short term recovery into long term planning of the community. Decision makers should consider the following for developing effective strategies: - i) Strategies for building capacities should be: -

- Cost effective and time effective

- Capacities should have more than one purpose. This will allow their implementation during normal and post disaster conditions.

- Capacities selected should be able to provide desired level of resilience. 
ii) Important factors to consider for selecting auxiliary capacities:

- Investment made in building capacities should relate with the probability of occurrence of the event.

- Capacities selected should be scalable.

- Multiple decisions made and their impact on overall recovery

- Tradeoff between capacity building and enhancing resilience

The strategies developed using this approach will help decision makers in the following ways: -

i) Greater insight over the budget and capacity requirement for optimal capacity building. For example, decision makers will be able to assess the budget and capacity requirement with respect to target resilience. For example, what will be the budget required if the hospital was to start the operations on $5^{\text {th }}$ day after disaster rather than on the $10^{\text {th }}$ day.

ii) Increase coordination among actors involved during recovery. Develop agreement with agencies for providing the auxiliary capacities.

iii) Encourage agencies to develop a disaster response budget.

iv) Plan for implementation of auxiliary support for meeting the infrastructure demands for providing the required support.

v) Integrate the decisions taken during emergency response and recovery into long term planning. This exercise will help in considering the implementation of permanent fixtures such as onsite water storage options such as water towers, private wells, etc.

\section{CONCLUSION}

Timely recovery is crucial for communities to recover after a disaster. Infrastructure should be able to provide adequate services for supporting different phases of recovery. The paper presents an optimization model of a decision support system for optimal building of infrastructure capacities. The optimization model is explained using a hypothetical situation where-in capacities are optimally selected to meet the daily water demands. This research will allow the decision makers to prepare better and effective response and recovery strategies for the community. Additionally, the decision makers will be able to better coordinate with actors involved. Through this research approach, the decisions taken during the different phases of recovery could be integrated in disaster planning of the anticipated disasters. Communities will be able to build capacities for each phase, i.e., emergency, short term and long term that will help them in enhancing resilience by expediting post disaster recovery.

\section{REFERENCES}

1. Abi-Samra, N., McConnach, J., Mukhopadhyay, S., and Wojszczyk, B. (2014). "When the Bough Breaks: Managing Extreme Weather Events Affecting Electrical Power Grids", Power and Energy Magazine, IEEE, vol. 12(5), 61-65.
2. Blake, S., Walker, R., and Walker, R (2011), "Potable Water Issues during Disaster Response and Recovery: Lessons Learned from Recent Coastal Disasters", Solutions to Coastal Disasters 2011, June 2011, 779794

3. Bruneau, M, Chang, S, Eguchi, R, Lee, G, O'Rourke, T, Reinhorn, A (2003), "A framework to quantitatively assess \& enhance the seismic resilience of communities", Earthquake Spectra, 19, 733-752.

4. Chang, S., Shinozuka M., (2004). Measuring Improvements in the disaster Resilience of Communities, EERI Spectra Journal, 20, (3), 739-755

5. Chiu, Y. T. (2013). "Typhoon Haiyan: Philippines faces long road to recovery", The Lancet, 382(9906), 1691-1692.

6. Comfort, L., K., McAdoo, B., Sweeney, P., Stebbins, S., Siciliano, M., D., Huggins, L., J., Serrant, T., Scheinert, S., Augenstein, J. Krenitsky, N. (2011). Transition from Response to Recovery: The January 12th, 2010 Haiti Earthquake. Earthquake Spectra, Vol. 27.1.

7. Deshmukh, A., and Hastak, M. (2014), "Ex-Ante Infrastructure Capacity Building For Improving Community Resilience To Natural Disasters.", Proceedings of the 1st International Conference on Infrastructure Failures and Consequences (ICIFC2014), 16-20 July 2014.

8. EIA. (2005). 2003 Commercial Buildings Energy Consumption Survey. Washington, DC: EIA. Available at http://www.eia.gov/consumption/commercial/reports/2 007/hospital-water-data-collection.cfm, Last accessed October 2014

9. Garnett, J. D., and Moore, M. (2010). "Enhancing disaster recovery: Lessons from exemplary international disaster management practices.", Journal of Homeland Security and Emergency Management, 7(1).

10. Lum, T., and Rhoda M. (2014), "Typhoon Haiyan (Yolanda): US and international response to Philippines disaster.", Congressional Research Service, www. fas. org/sgp/crs/row 43309, retrieved November (2014).

11. Miles, S., B., and Chang, S., E. (2006), "Modeling Community Recovery from Earthquakes", Earthquake Spectra: May 2006, Vol. 22, No. 2, pp. 439-458.

12. Oh, E. H., Deshmukh, A., and Hastak, M. (2012). "Criticality Assessment of Lifeline Infrastructure for Enhancing Disaster Response.", Natural Hazards Review, vol. 14(2), 98-107.

13. Reed M., K. (1998), "Disaster preparedness pays off.", Journal of Nursing Administration. June 1998, vol 28(6):25-31.

14. Siders C, and Jacobson, R. (1998), "Flood disaster preparedness: A retrospect from Grand Forks", North Dakota. Journal of Health and Risk Management. 1998 vol.18(2):33-40.

15. Sumathi, S., and Paneerselvam, S. (2010). "Computational intelligence paradigms: theory \& applications using MATLAB”, CRC Press. 
16. United Nations Office for Disaster Risk Reduction (UNISDR) (2011), "Basics of capacity development for disaster risk reduction" <http://www.unisdr.org/we/inform/publications/18061 $>$, Visited $18^{\text {th }}$ Nov, 2012

17. Vugrin E., Warren E., Ehlen M., and Camphouse R. (2010), A Framework for Assessing the Resilience of Infrastructure and Economic Systems, In K. Gopalakrishnan and S. Peeta (Ed.), Sustainable and Resilient Critical Infrastructure Systems, pp.(77-116). Springer.

18. Welter, G., Socher, M., Needham, P., Bieber, S., \& Bonnaffon, H. (2013). "Cross-sector emergency planning for water supply utilities and healthcare facilities.", Journal of Healthcare Risk Management, vol. 32(4), 5-14. 